Brit. Heart F., 1967, 29, 453.

CASE REPORTS

\title{
Successful Early Repair of Acquired Ventricular Septal Defect After Myocardial Infarction
}

\author{
M. HONEY, J. R. BELCHER, M. HASAN, AND J. R. P. GIBBONS
}

From the London Chest Hospital, London E.2

Successful repair of an acquired ventricular septal defect following myocardial infarction was first reported in 1962. Recently Barnard and Kennedy (1965) have reviewed 14 patients with post-infarction ventricular septal defect in whom surgical closure was attempted; 7 survived more than 6 weeks after operation. They found that those whose defects were closed 5 weeks or more after infarction survived the operation, but that those requiring emergency operation soon after infarction died. The best long-term results were obtained in those whose operations were delayed 3 months or more. However, more than 90 per cent of all patients die within a year of septal rupture, and most of these die within 2 months (Sanders, Kern, and Blount, 1956). It is clear that surgical repair should be considered in all patients who have a hæmodynamically significant shunt through an acquired ventricular septal defect; ideally this should be done at least 6 and preferably 12 weeks after infarction, but, in view of the very high early mortality on medical treatment, nothing can be lost by attempting closure at an earlier stage if the patient is deteriorating.

The following report concerns a patient in whom the defect was successfully repaired 27 days after infarction, and 20 days after the presumed time of septal rupture.

\section{Case Report}

A man, aged 52, had left-sided chest pain, with nausea and sweating, on September 10, 1965. On September 17, he was more breathless and had a fainting episode; on this occasion his doctor heard a loud præcordial systolic murmur for the first time.

On admission to the Whittington Hospital on September 20 under the care of Dr. T. St M. Norris, he was pale and sweating with a regular tachycardia and a raised venous pressure. The blood pressure was 120/100 mm. Hg. The heart was not clinically enlarged but a loud pansystolic murmur with thrill was loudest in the fourth left intercostal space near the sternum. There were bilateral basal râles, and a chest $x$-ray film showed pulmonary venous congestion with a small right pleural effusion. The electrocardiogram showed a recent posterior myocardial infarct. The diagnosis of ruptured interventricular septum was made; he improved at first on routine medical treatment, but signs of right-sided heart failure increased, and he was transferred to the London Chest Hospital on September 28 for consideration of surgical repair.

At this time he was orthopnœic, and had signs of congestive cardiac failure with raised jugular venous pressure $(10 \mathrm{~cm}$.$) , enlarged tender liver, and cdema of$ both ankles. The pulse was rapid $(110 / \mathrm{min}$.) and the blood pressure 130/100 mm. Hg. The murmur and thrill were unchanged. He had several carious teeth and gross gingival infection. The chest $x$-ray film showed no cardiac enlargement (CTR 48\%); there was severe pulmonary congestion with bilateral hilar and basal clouding and small pleural effusions. The electrocardiogram showed normal sinus rhythm; $Q$ waves, slightly raised ST segments, and inverted $T$ waves in leads II, III, aVF, V6, and V7 indicated fairly recent postero-lateral infarction. Treatment was continued with digoxin, mersalyl, and frusemide, but without benefit.

Cardiac catheterization (see Table) was undertaken to confirm the clinical diagnosis; it was essential to exclude mitral regurgitation due to papillary muscle rupture, since the surgical approach to this lesion would have been different. A large left-to-right shunt at ventricular level was found, and inadvertent passage of the catheter into the left ventricle confirmed the presence of an interventricular communication. Raised right and left atrial and ventricular diastolic pressures indicated biventricular failure.

Operation (J. R. B.). The defect was closed on October 7 under cardiopulmonary bypass (Melrose453 
TABLE

RESULTS OF CARDIAC CATHETERIZATION

\begin{tabular}{|c|c|c|c|c|}
\hline \multirow[b]{2}{*}{ Site } & \multicolumn{2}{|c|}{ Pre-operative } & \multicolumn{2}{|c|}{ Post-operative } \\
\hline & $\begin{array}{c}\text { Pressure } \\
\left(\mathrm{mm} . \mathrm{Hg}^{\star}\right.\end{array}$ & $\begin{array}{c}\text { Oxygen } \\
\text { saturation }(\%)\end{array}$ & $\begin{array}{c}\text { Pressure } \\
(\mathrm{mm} . \mathbf{H g})^{\star}\end{array}$ & $\begin{array}{c}\text { Oxygen } \\
\text { saturation }(\%)\end{array}$ \\
\hline $\begin{array}{l}\text { Superior vena cava } \\
\text { Inferior vena cava } \\
\text { Right atrium } \\
\text { Right ventricle } \\
\text { Pulmonary artery } \\
\text { Pulmonary artery wedge } \\
\text { Left ventricle } \\
\text { Brachial artery }\end{array}$ & $\begin{array}{c}- \\
\overline{1} \\
\text { a } 12 \text { v } 7 \\
\text { x } 0 \\
40 / 12 \\
45 / 12 \\
\text { a } 18, \text { v } 26 \\
\text { x } 10, \text { y } 10 \\
90 / 18 \\
90 / 70\end{array}$ & $\begin{array}{c}50 \\
36 \\
48,49,49 \\
81,91 \\
77,80,82 \\
- \\
88 \\
92,93\end{array}$ & $\begin{array}{c}\overline{-} \\
\text { a } 2 \cdot 5, \mathrm{v} 2, \\
\mathrm{x}-1, \mathrm{y}-1 \cdot 5 \\
20 / 2 \\
17 / 2 \\
\text { mean } 1-2 \\
\text { (non-phasic) } \\
\overline{92 / 60}\end{array}$ & $\begin{array}{c}\frac{62,64}{62, \overline{65}, 66} \\
68,72 \\
\frac{64}{-} \\
\frac{96}{6}\end{array}$ \\
\hline & \multicolumn{2}{|c|}{ Pulmonary-systemic flow ratio $3 \cdot 4: 1$} & & \\
\hline
\end{tabular}

^ Reference level: sternal angle.

oblique incision in the right ventricle revealed a defect about $5 \mathrm{~cm}$. circumference $(1.6 \mathrm{~cm}$. diameter) in the muscular septum near the apex of the heart; its margin appeared surprisingly healthy and held sutures well. A teflon patch was placed over the defect and secured with 8 or 9 interrupted stitches. After closure of the heart and rewarming, sinus rhythm was restored by direct current countershock, but ventricular fibrillation repeatedly recurred and four shocks were required before stable sinus rhythm was established.

Post-operative Course. Tracheotomy was required on the first post-operative day and artificial ventilation (Beaver Pulmoflator) was continued for seven days. Consciousness returned promptly after operation, but there were transient signs of a right hemiparesis which recovered completely. A slightly raised venous pressure and slight ankle œdema required continued treatment with digoxin and oral diuretics, but these signs of mild cardiac failure cleared within three weeks. Anticoagulant treatment with warfarin was started, and antibiotics (ampicillin and cloxacillin) were given from the time of operation until discharge from hospital. Six weeks after operation, 12 carious teeth were extracted under vancomycin cover.

A soft apical pansystolic murmur was audible immediately after operation, and became louder (grade 3/6) during the next few weeks; this was less well heard at the left border of the sternum and was initially attributed to mitral regurgitation. At cardiac catheterization (see Table), the pulmonary artery wedge pressure was normal; though the oxygen analyses revealed no significant shunt, one right ventricular sample suggested that there might be a small residual defect; on these findings it was felt that left ventricular angiography was not necessary.

He returned home on November 27 still taking digoxin, a diuretic, and warfarin. When last seen (December 21) he was well and able to walk without chest pain or undue dyspnœa; the venous pressure was slightly raised but there was no œdema. He died suddenly at home on January 8, 1966.

Necropsy. The heart weighed $490 \mathrm{~g}$. There was a large fibrous scar with slight aneurysmal bulging consequent upon a full-thickness infarct of the diaphragmatic wall of the left ventricle; scarring also involved the posterior half of the septum and part of the right ventricle. The teflon patch was securely in place and covered by endothelium; the septum was intact except for a very small round smooth-edged hole $(2 \mathrm{~mm}$. diameter). There was severe atheroma of both coronary arteries and old thrombotic occlusion of the right artery distal to a point $2 \mathrm{~cm}$. from its origin.

\section{Discussion}

Our experience with this patient demonstrates that it is possible to repair successfully a ruptured ventricular septum within 4 weeks of the occurrence of an extensive myocardial infarct. Though he lived long enough to leave hospital, he died 3 months after the operation, presumably from the effects of the severe underlying coronary arterial disease. Long-term prognosis in these patients is necessarily unpredictable, and the risk of sudden death from recurrent infarction or ventricular fibrillation should not deter one from advising the surgical repair of an acquired ventricular septal defect when this is an immediate danger to life.

The chances of a successful operation are greatest if closure can be delayed until three months after septal rupture; but it is usually not possible to wait as long as this, since most patients are dead within eight weeks. Long survival without operation depends upon a combination of three factors: a relatively small defect, good myocardial function, and the absence of further coronary attacks; Landale and Schlappi (1962) have reported a patient who survived for 13 years with a $2 \times 1 \mathrm{~cm}$. defect. Conversely, early death results if the acquired shunt is a very large one or if left ventricular function is grossly impaired. It is probable that the lower mortality of late operations is not due so much to the progress of reparative fibrosis of the infarcted muscle surrounding the defect, as to the fact that the worst risk cases have already died. 
In our patient there was a large defect, but despite clinical and hæmodynamic evidence of progressive heart failure, the left ventricle was capable of maintaining an output adequate for survival; it was, therefore, reasonable to expect that with closure of the defect, myocardial function would be good enough to sustain the circulation in the postoperative period and to ensure a worth-while clinical result. If, on the other hand, the defect is a small one and the shunt insignificant, and despite this the heart is failing, then clearly operative repair could achieve nothing and would almost certainly prove fatal. It is thus necessary not only to confirm the diagnosis of acquired ventricular septal defect before operation, but also to assess the size of the shunt.

Septal rupture must be distinguished from mitral regurgitation due to rupture of a papillary muscle, or to left ventricular failure or papillary muscle dysfunction. The most helpful clinical feature is the site of the murmur: the pansystolic murmur of an acquired septal defect, like that of the congenital lesion, is usually loudest at the lower left sternal border, and is often accompanied by a thrill (Sanders et al., 1956). However, since the defect is in the muscular septum, the murmur may be well heard at the apex and in the axilla (Harrison et al., 1961). The murmur of papillary muscle rupture is also pansystolic, but is usually, though not always, loudest at the apex, and is very rarely associated with a thrill; a diastolic murmur is quite common (Sanders, Neubuerger, and Ravin, 1957; Robinson, Stannard, and Long, 1965). Papillary muscle rupture occurs most frequently with posterior infarction, and septal rupture with anterior infarction; conduction defects are commoner with rupture of the septum (Sanders et al., 1956, 1957), but these cardiographic features are relatively unhelpful in the individual patient. Either lesion may precipitate left ventricular failure, but characteristically this is more sudden and dramatic in onset after rupture of a papillary muscle. In our patient, the site and intensity of the murmur suggested the correct diagnosis. On the other hand, the radiological appearances were those of pulmonary venous congestion only; the pulmonary arterial branches were not abnormally prominent, and it is evident that pulmonary plethora does not develop immediately flow is increased.

Cardiac catheterization confirmed the diagnosis, and also demonstrated a large left-to-right shunt. Catheter findings in post-infarction rupture of the interventricular septum have been reported by numerous authors (Muller et al., 1950; Cooley et al., 1957; Gottsegen et al., 1957; Shickman, Fields, and Pearce, 1959; Gerbaux et al., 1960; Rubenstein and Levinson, 1961; Boicourt et al., 1962; Bressie et al.,
1962; Collis et al., 1962; Dobell et al., 1962; Lee, Cardon, and Slodki, 1962; Payne, Hunt, and Kirklin, 1963; Davison et al., 1964). All those six patients whose defects were later successfully repaired had left-to-right shunts of 2.7:1 or more (Boicourt et al., 1962; Bressie et al., 1962; Collis et al., 1962; Davison et al., 1964; Payne et al., 1963; and our case). The defects in four of these were large $(2 \times 1.5 \mathrm{~cm} ., 3 \times 1.5 \mathrm{~cm}$., $2.5 \mathrm{~cm}$. diameter, $5 \mathrm{~cm}$. circumference); one (Payne et al.) was only $0.9 \mathrm{~cm}$. in diameter, and Boicourt et al. (1962) described the defect in their case as flap-like, but Levene (1960), in his pathological study of rupture of the heart, pointed out that myocardial tears are often oblique, and that the epicardial or right ventricular opening may be inconspicuous. These observations support the view that surgical repair is more likely to be successful when the defect is physiologically a large one; in such a case the mere fact of survival long enough for surgery to be considered indicates reasonable left ventricular function.

Catheterization has been employed with some reluctance because of the potential hazards of perforation of the heart with the catheter, and of ventricular tachycardia or fibrillation. There were no deaths due to the procedure in the reported cases, and the risks are certainly acceptable, if the investigation is done with surgical correction in view, by an experienced operator with the utmost gentleness and with facilities for emergency resuscitation readily available.

\section{Summary}

A case of acquired ventricular septal defect following posterior myocardial infarction is reported. Cardiac catheterization confirmed the clinical diagnosis and showed a large shunt and hæmodynamic evidence of biventricular failure. Because of increasing signs of heart failure, surgical repair (using a teflon patch) was undertaken 27 days after infarction, and 20 days after the probable time of septal rupture. The patient survived the operation but died 3 months later, presumably from ventricular fibrillation. Post-operative catheterization showed an insignificant shunt. Necropsy confirmed that there was a minute residual defect, but the repair was otherwise intact, and the patch was covered by endothelium.

It is suggested that early operation should be considered if clinical deterioration continues despite adequate medical treatment, and a large shunt can be demonstrated. The patient with a small shunt well tolerated does not require surgical treatment; when there is left ventricular failure though the shunt is only a small one, the patient is unlikely to survive operation. 
We wish to thank Dr. T. St M. Norris and Dr. H. E. S. Pearson for referring this patient to us, and Dr. D.P. Winstanley for the post-mortem examination.

\section{References}

Barnard, P. M., and Kennedy, J. H. (1965). Postinfarction ventricular septal defect. Circulation, 32, 76.

Boicourt, O. W., Ritzmann, L. W., Chase, J. D., Starr, A., and McCord, C. W. (1962). Rupture of the infarcted interventricular septum; surgical repair with survival. Circulation, 26, 1321.

Bressie, J. L., Snyder, D. D., Williams, G. R., Smiley, R. H., and Campbell, G. S. (1962). Ruptured interventricular septum; successful repair after myocardial infarction. f. Amer. med. Ass., 182, 1042.

Collis, J. L., Mackinnon, J., Raison, J. C. A., and Whittaker, S. R. F. (1962). Repair of acquired interventricular septal defect following myocardial infarction. Lancet, 2, 172.

Cooley, D. A., Belmonte, B. A., Zeis, L. B., and Schnur, S. (1957). Surgical repair of ruptured interventricular septum following acute myocardial infarction. Surgery, 41, 930.

Davison, T., Degenshein, G. A., Yuceoglu, Y. Z., Reyes, A. L., Levowitz, B., Dresdale, D. T., and Kantrowitz, A. (1964). Repair of ventricular septal defect following myocardial infarction. Ann. Surg., 160, 33.

Dobell, A. R. C., Scott, H. J., Cronin, R. F. P., and Reid, E. A. S. (1962). Surgical closure of interventricular septal perforation complicating myocardial infarction. F. thorac. cardiovasc. Surg., 43, 802.

Gerbaux, A., Maurice, P., Gras, H., and Lenègre, J. (1960). Etude clinique et hémodynamique de deux cas de rupture septale par infarctus myocardique avec survie prolongée. Arch. Mal. Cour, 53, 1278.

Gottsegen, G., Szám, I., Romoda, T., and Matheides, P. (1957). Perforation of the infarcted septum; observations on pathology and hæmodynamics. Acta med. scand., 158, 156.
Harrison, R. J., Shillingford, J. P., Allen, G. T., and Teare, D. (1961). Perforation of interventricular septum after myocardial infarction. Brit. med. f., 1, 1066.

Landale, D. G., and Schlappi, J. C. (1962). Thirteen-year survival with acquired interventricular septal defect after myocardial infarction. Amer. Heart f., 64, 33.

Lee, W. Y., Cardon, L., and Slodki, S. J. (1962). Perforation of infarcted interventricular septum. Arch. intern. Med., 109, 731.

Levene, A. (1960). Spontaneous rupture of the heart. Brit. Heart f., 22, 660.

Muller, O., Humerfelt, S., Rasmussen, H., and Storstein, $O$. (1950). Perforation of the ventricular septum following myocardial infarction. Acta cardiol. (Brux.), 5, 633.

Payne, W. S., Hunt, J. C., and Kirklin, J. W. (1963). Surgical repair of ventricular septal defect due to myocardial infarction. Report of a case. f. Amer. med. Ass., 183, 603.

Robinson, J. S., Stannard, M. M., and Long, M. (1965). Ruptured papillary muscle after acute myocardial infarction. Amer. Heart f., 70, 233.

Rubenstein, P., and Levinson, D. C. (1961). Acquired interventricular septal defects due to myocardial infarction and nonpenetrating trauma to the chest. Amer. f. Cardiol., 7, 277.

Sanders, R. J., Kern, W. H., and Blount, S. G. (1956). Perforation of the interventricular septum complicating myocardial infarction: a report of 8 cases, one with cardiac catheterization. Amer. Heart f., 51, 736.

-, Neubuerger, K. T., and Ravin, A. (1957). Rupture of papillary muscles: occurrence of rupture of the posterior muscle in posterior myocardial infarction. Dis. Chest, 31, 316.

Shickman, M. D., Fields, J., and Pearce, M. L. (1959). Repair of ruptured interventricular septum complicating acute myocardial infarction. Arch. intern. Med., 103, 140. 